\title{
Effects of Combination Antihypertensive Therapy Candesartan and Amlodipine on Blood Pressure and Diastolic Function Parameters - Rationale and Design of a Clinical Study
}

\author{
Denislava Hristova ${ }^{1}$, Iana Simova ${ }^{1,2 *}$, Vladimir Kornovski ${ }^{3}$, Nikolay Dimitrov ${ }^{1,3}$ and \\ Toni Vekov ${ }^{2,4}$ \\ ${ }^{1}$ Heart and Brain Centre of Excellence, University Hospital, Bulgaria \\ ${ }^{2}$ Bulgarian Cardiac Institute, Bulgaria \\ ${ }^{3}$ Heart and Brain Centre of Excellence, University Hospital, Bulgaria \\ ${ }^{4}$ Medical University, Bulgaria
}

*Corresponding author: Iana Simova, professor, Chief Executive Officer of the Bulgarian Cardiac Institute, Head of Cardiology Department, Head of a scientific group for post-COVID syndrome, Heart and Brain Centre of Excellence University Hospital, 2 Pier Curie Str, Pleven 5800, Bulgaria.

To Cite This Article: Denislava Hristova, Iana Simova, Vladimir Kornovski, Nikolay Dimitrov, Toni Vekov, Effects of Combination Antihypertensive Therapy Candesartan and Amlodipine on Blood Pressure and Diastolic Function Parameters - Rationale and Design of a Clinical Study. Am J Biomed Sci \& Res. 2021 - 12(2). AJBSR.MS.ID.001733. DOI: 10.34297/AJBSR.2021.12.001733.

Received: 眥 February 02, 2021; Published: 㘹 March 12, 2021

\begin{abstract}
Left ventricular diastolic dysfunction is the underlying pathophysiological disorder in patients with heart failure and preserved left ventricular ejection fraction. According to the latest guidelines of the European Society of Cardiology, the diagnosis requires the presence of three factors:

I. Symptoms and signs of heart failure

II. Preserved or slightly abnormal systolic function - ejection fraction over 50\%

III. Evidence of diastolic dysfunction - measured via invasive or non-invasive methods

Arterial hypertension is a socially significant disease afflicting an increasing part of the population. It is defined as office values of systolic blood pressure above $140 \mathrm{mmHg}$ and/or values of diastolic pressure above $90 \mathrm{mmHg}$. It is an independent nosological unit, but also a major risk factor for the development of cardiovascular, cerebrovascular and kidney diseases.
\end{abstract}

This article presents the main parameters for determining diastolic function, the characteristics of the most commonly used medications for the treatment of arterial hypertension and a design of a clinical study based on the effects of combination antihypertensive therapy candesartan and amlodipine on diastolic function parameters and on the values of systolic and diastolic blood pressure.

Keywords: Diastolic function; Diastolic dysfunction; Arterial hypertension

\section{Introduction}

The term diastole comes from the Greek words dia and stellen, which together (diastellen) mean separation [1]. Normal diastolic function is left ventricular filling at normal pulmonary capillary

pressure. Diastolic dysfunction is impaired filling of the chamber with a compensatory increase in left atrial pressure [2]. It is a result of impaired relaxation and increased stiffness (reduced compliance) of the left ventricle (LV). Instrumental methods for diagnosis are: 
A. Radionuclide angiography: It is carried out by inserting a radioisotope element into the blood and monitoring its passage through the heart through a gamma camera, which registers the pulses emitted by it. The left ventricular filling is proportional to the registered pulses. Pulses from many cardiac cycles are superimposed on each other, synchronized with ECG. The indicators are determined: maximum left ventricular filling rate (peak filling rate - PFR), time from the start of the diastole to reaching the maximum left ventricular filling rate (time to peak filling rate TPFR). The rapid filling of the left ventricle is usually assessed through PFR. However, in tachycardia, due to the superposition of the atrial systole on the rapid filling, it is assessed by the maximum filling rate in the first third or first half of the diastole. Disadvantages of the study are the use of radioactive substances, the need for a constant RR interval for the pulses superposition, the inability to assess the variability of the diastolic function from stroke to stroke.

Invasive testing allows simultaneous measurement of pressures and volumes. Consecutive left ventricular volumes during one diastole are measured in the first contraction after contrast injection when the contour of the ventricle is clearly visible in each frame. In some cases, echocardiography is performed simultaneously to continuously determine left ventricle volume [2]. The main indicators determined are the mean pulmonary-capillary pressure, mean left atrial pressure, mean LV diastolic pressure and LV tele diastolic pressure.

B. Echocardiography plays a key role in the diagnosis of diastolic dysfunction as it is easy to use, non-invasive and accessible. LV filling pressures and the degree of diastolic dysfunction can be reliably determined by several parameters [2]. The main parameters and their characteristics are presented in Table 1. Age, clinical data, heart rate, blood pressure, 2D and Doppler finding in terms of LV volumes, wall thickness, ejection fraction (EF), left atrial volume, presence and severity of mitral valve disease are taken into consideration with the assessment of diastolic function. The quality of the Doppler signal is of particular importance. Suboptimal, it should not be used to formulate conclusions [3].

Table 1: Main parameters used in the diagnosis of LV diastolic dysfunction, their access and analysis:

\begin{tabular}{|c|c|c|}
\hline Variable & Acquisition & Analysis \\
\hline Mitral peak E-velocity & $\begin{array}{l}\text { 1. Apical four-chamber view with color image of the blood flow for } \\
\text { optimal alignment of the PW doppler with blood flow } \\
\text { 2. PW Doppler volume sample (1-3 mm axial size) between mitral } \\
\text { leaflets tips }\end{array}$ & $\begin{array}{l}\text { Peak velocity in early diastole at the leading } \\
\text { edge of the spectral waveform }\end{array}$ \\
\hline Mitral peak A-velocity & $\begin{array}{l}\text { 3. Use low wall filter setting }(100-200 \mathrm{MHz}) \text { and low signal gain } \\
\text { 4. Optimal spectral waveforms should not display spikes or feath- } \\
\text { ering }\end{array}$ & $\begin{array}{l}\text { Peak velocity in late diastole at the leading } \\
\text { edge of the spectral waveform }\end{array}$ \\
\hline E/A ratio & See above for E and A-velocity access techniques & \\
\hline $\begin{array}{l}\text { E-velocity deceleration } \\
\text { time }\end{array}$ & $\begin{array}{l}\text { 1. Apical four-chamber view: PW Doppler volume sample between } \\
\text { mitral leaflets tips }\end{array}$ & $\begin{array}{l}\text { Time interval from the peak E-wave along the } \\
\text { LV filling curve extrapolated to the baseline } \\
\text { zero velocities }\end{array}$ \\
\hline $\begin{array}{l}\text { e` mitral annular veloci- } \\
\text { ty derived with PW TDI }\end{array}$ & $\begin{array}{l}\text { 1. Apical four-chamber view: PW Doppler sample volume (usually } 5-10 \mathrm{~mm} \\
\text { axial size) at the lateral and septal basal regions so that the mean e` velocity } \\
\text { can be calculated } \\
\text { 2. Use the system presets for wall filter and the lowest signal gain }\end{array}$ & $\begin{array}{l}\text { Peak modal velocity in early diastole at the } \\
\text { leading edge of the spectral waveform }\end{array}$ \\
\hline Mitral E / e`ratio & See above for selecting access for $\mathrm{E}$ and $\mathrm{e}$ 'velocities & $\begin{array}{l}\text { Mitral valve E velocity divided by the mitral } \\
\text { annular velocity e }\end{array}$ \\
\hline Left atrium size & Measured in an apical four-chamber view & \\
\hline Left atrium area & Measured in an apical four-chamber view & \\
\hline Left atrium volume & $\begin{array}{l}\text { 1. Apical four-chamber view and two-chamber view: still frames are } \\
\text { obtained 1-2 frames before mitral valve opening } \\
\text { 2. LA volume must be measured in dedicated views where LA length and } \\
\text { transverse diameters are maximum }\end{array}$ & $\begin{array}{l}\text { Disc method or length / area method and } \\
\text { adjustment for BSA. The left atrial appendage } \\
\text { or pulmonary veins are not included. }\end{array}$ \\
\hline $\begin{array}{l}\text { Systolic (S) velocity of } \\
\text { the pulmonary veins }\end{array}$ & $\begin{array}{l}\text { 1. Apical four-chamber view color image to assist in positioning the sample } \\
\text { volume by PW doppler (1-3 mm axial size }) \\
\text { 2. Sample volume located at a depth of } 1-2 \mathrm{~cm} \text { in the right or left upper } \\
\text { pulmonary vein } \\
\text { 3. Use low wall filter settings }(100-200 \mathrm{MHz}) \text { and low signal gain }\end{array}$ & $\begin{array}{l}\text { Peak modal velocity in early systole at the } \\
\text { leading edge of the spectral waveform }\end{array}$ \\
\hline
\end{tabular}




\begin{tabular}{|c|c|c|}
\hline $\begin{array}{l}\text { Diastolic (D) velocity of } \\
\text { the pulmonary veins }\end{array}$ & Same as for $\mathrm{S}$ wave of the pulmonary vein & $\begin{array}{l}\text { Peak modal velocity in early diastole after } \\
\text { mitral valve opening at the leading edge of } \\
\text { the spectral waveform }\end{array}$ \\
\hline $\mathrm{S} / \mathrm{D}$ ratio & See above for access to the $S$ and $D$ velocities of the pulmonary vein & S-wave velocity divided by D-wave velocity \\
\hline $\begin{array}{l}\text { CW Doppler: } \\
\text { Tricuspid velocity of the } \\
\text { systolic jet }\end{array}$ & $\begin{array}{l}\text { 1. Parasternal and apical four-chamber view with color imaging to obtain } \\
\text { the highest Doppler velocity aligned with CW } \\
\text { 2. Adjust gain and contrast so that the display shows the full spectral enve- } \\
\text { lope without signal spikes or feathering. }\end{array}$ & $\begin{array}{l}\text { Peak modal velocity during systole at the } \\
\text { leading edge of the spectral waveform }\end{array}$ \\
\hline
\end{tabular}

Nearly 2/3 of patients referred for echocardiography for various symptoms, coronary heart disease, ECG changes or arrhythmia, with preserved $\mathrm{EF}$, have left ventricular diastolic dysfunction, which is an independent prognostic death factor. Carmel M. Halley et al. analyze the clinical and echocardiographic data of over 36,000 patients with preserved LV EF. Diastolic dysfunction was found in $65.2 \%$ of them - $60 \%$ mild, $4.8 \%$ - moderate, $0.4 \%$ - severe. Mortality was $16 \%$ during the 6.2-year follow-up, with an association with the degree of diastolic dysfunction: $7 \%$ in people with normal function, $21 \%, 24 \%$ and $39 \%$ - respectively for patients with mild, moderate, and severe diastolic dysfunction. Therefore, proper assessment and treatment of patients is particularly important [4].

Arterial hypertension is a socially significant disease afflicting an increasing part of the population. It is an independent nosological unit, but also a major risk factor for the development of cardiovascular, cerebrovascular and kidney diseases. The results of a meta-analysis of 61 prospective studies show that reducing systolic blood pressure (BP) by $10 \mathrm{mmHg}$ within 10 years reduces the risk of stroke by $40 \%$ and the risk of death from coronary heart disease by $30 \%$ [5].

The effects of hypertension are also visible in the structure of the cardiac chambers - LV hypertrophy, impaired LV relaxation, left atrial dilatation, increased risk of arrhythmias, especially atrial fibrillation, and the development of heart failure with preserved EF and heart failure with reduced EF [3].

The guidelines for treatment of AH from 2018 recommends combination therapy as an initial strategy. The first step involves a combination of a blocker of the renin-angiotensin system angiotensin-converting enzyme inhibitors (ACE-inhibitors) or angiotensin receptor blockers (ARBs) and a calcium antagonist (CA) or diuretic. Fixed combinations are preferred to improve compliance [6].

ARBs have important advantages over ACE inhibitors: they are the most tolerable antihypertensive medications, more effective in inhibiting the renin-angiotensin system because they act selectively at the AT-1 receptor level; they do not affect the kallikrein-kinin system; have protective and preventive properties in terms of organs and metabolism.
The effects of the AT- 1 receptor are vasoconstriction, sodium retention, activation of the sympathetic nervous system, vascular inflammation, cardiovascular remodeling, activation of collagen and fibrin synthesis. By blocking this receptor, the opposite effects and regression of pathological conditions are observed [7-11].

Candesartan occupies a special place among ARBs. Its unique properties are rapid resorption and maximum effect within 4 hours after ingestion; long half-life, which makes a single daily intake possible; highest affinity for binding to the AT-1 receptor, as well as the slowest dissociation, which provides a permanent effect, avoiding sharp diurnal fluctuations; combined excretion gastrointestinal tract and kidneys; decrease in peripheral vascular resistance, no change in heart rate, stroke volume and heart index; without orthostatic effects; reduces the risk of developing newonset type 2 diabetes and reduces the progression of existing diabetic retinopathy [8-12].

Calcium channel blockers have been shown to improve diastolic function by reducing the concentration of calcium in the cytoplasm, causing myocardial relaxation, or indirectly by lowering peripheral vascular resistance and $\mathrm{BP}$.

The most widely used calcium antagonist in clinical practice is amplodipine. This is due to its many properties: the longest plasma half-life among calcium antagonists, gradual and long-lasting effect, without postural hypotension, tachyphylaxis or rebound effect; preserves the circadian characteristics of BP, negligible effect on heart rate and conduction, metabolically neutral, increases renal blood flow and glomerular filtration $[8,9,11]$.

\section{Study Objective}

To evaluate the effect of treatment with a combination of candesartan and amlodipine (Bilamcar, Tchaikapharma High Quality Medicines) in patients with suboptimal BP control and diastolic LV dysfunction.

\section{Tasks}

1. To investigate the effect of antihypertensive treatment with the combination of candesartan and amlodipine on systolic and diastolic blood pressure.

2. To compare systolic function before and after treatment. 
3. To examine diastolic function before and after treatment.

4. To examine the change in the thickness of the LV walls before and after treatment.

\section{Study design}

The study was initiated in July 2020 in 'Heart and Brain' Centre of Excellence, Pleven. It included patients hospitalized in the Cardiology Clinic who had suboptimal BP control, hypertension not previously treated with ARB and/or calcium antagonist, manifestations of heart failure, patients with preserved LV EF or intermediate LV EF, LV hypertrophy, echocardiographic criteria for diastolic dysfunction.

\section{Exclusion criteria}

Patients with heart failure with reduced LV EF and secondary arterial hypertension.

After initial assessment, which includes indirect measurement of systolic and diastolic blood pressure, echocardiographic examination and determination of parameters of diastolic dysfunction were analyzed: mitral peak E-velocity and A-velocity, E/A ratio, E-velocity deceleration time, e` mitral annular velocity derived with PW TDI, mitral E / e` ratio, size, area and volume of the left atrium, tricuspid velocity of the systolic jet, systolic (S) and diastolic (D) velocity of the pulmonary veins and S/D ratio. In patients with diastolic dysfunction and suboptimal BP control we initiated candesartan + and amlodipine therapy. Patients were followed-up for one month after starting the treatment, when reassessment of blood pressure and echocardiographic parameters for diastolic dysfunction was performed.

\section{Research methods}

1. Indirect measurement of systolic and diastolic blood pressure with a sphygmomanometer - we recorded the average value of a triple BP measurement in a sitting position. We compared the values on admission to the clinic with those on treatment with a combination of candesartan and amlodipine.

2. Echocardiography - an integral part of the routine assessment of patients with symptoms of dyspnea or heart failure. It was performed by one-dimensional (M-mode), two-dimensional, conventional Doppler echocardiography and tissue Doppler echocardiography. The main parameters we used were: mitral peak E-velocity and A-velocity, the E/A ratio, E velocity deceleration time, derived with the PW TDI, e`mitral annular velocity, mitral ratio E/ $\mathrm{e}^{\prime}$, size, area and volume of the left atrium, tricuspid velocity of the systolic jet, systolic (S) and diastolic (D) velocity of the pulmonary veins and S/D ratio. Table. 1 presents the characteristics of each of them. One parameter outside the normal range did not mean diastolic dysfunction and the indices should not be used in isolation. We sought consistency between two or more parameters, and the interpretation was in the context of the clinical picture.
To assess diastolic dysfunction, four indicators were required:

1. Septal e`velocity $<7 \mathrm{~cm} / \mathrm{s}$ or lateral e`velocity $<10 \mathrm{~cm} / \mathrm{s}$

2. Average $\mathrm{E} / \mathrm{e}^{`}>14$

3. Indexed volume of $\mathrm{LA}>34 \mathrm{ml} / \mathrm{m}^{2}$

4. Tricuspid valve velocity $>2.8 \mathrm{~cm} / \mathrm{s}$

If less than $50 \%$ of the indicators exceeded the limit values, then diastolic function was normal. If more than $50 \%$ of the indicators exceeded the limit values, then diastolic dysfunction is present. If exactly $50 \%$ of the indicators exceeded the limit values, then the diastolic function could be determined (Figure 1).

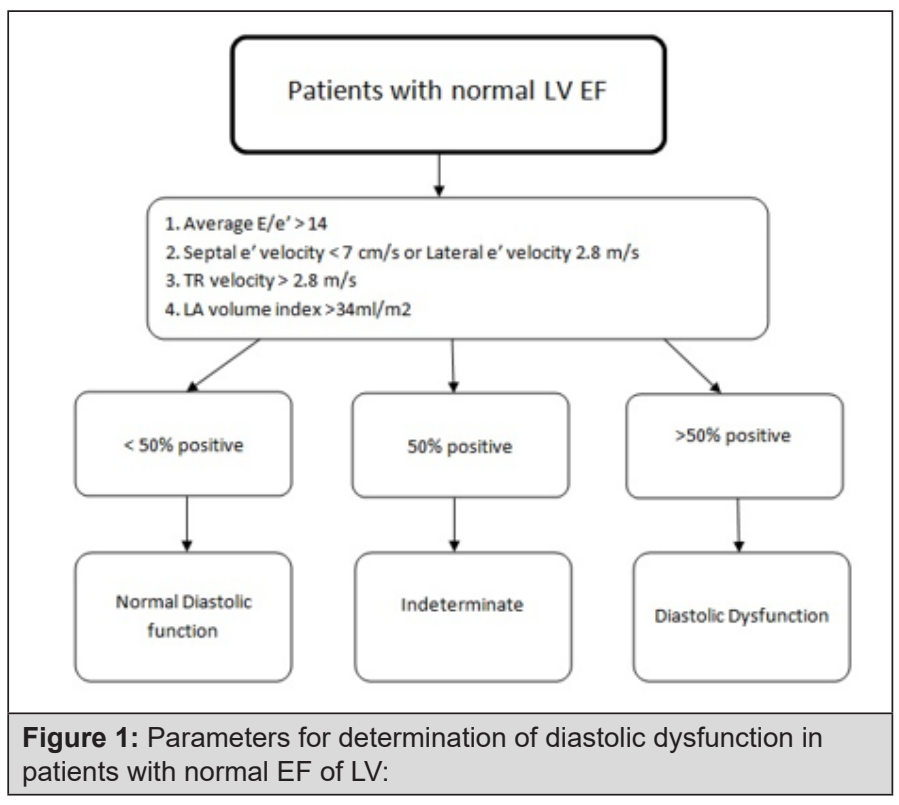

The degree of dysfunction is essential. For this purpose, the velocity of the blood flow through the mitral valve was used. If E/A $\leq 0.8$ and $\mathrm{E} \leq 50 \mathrm{~cm} / \mathrm{s}$, then there is diastolic dysfunction I degree. At $\mathrm{E} / \mathrm{A} \leq 0.8$ and $\mathrm{E}>50 \mathrm{~cm} / \mathrm{s}$ or $0.8<\mathrm{E} / \mathrm{A}<2$, additional measurements had to be made, such as:

a. Average E/e`>14

b. Indexed volume of $\mathrm{LA}>34 \mathrm{ml} / \mathrm{m}^{2}$

c. Tricuspid valve velocity $>2.8 \mathrm{~cm} / \mathrm{s}$

If two or three of these parameters were negative, then diastolic dysfunction I degree was determined. If two or three parameters were positive, diastolic dysfunction is II degree. If the value of E/A> 2 , then the diastolic dysfunction was III degree (Figure 2).

\section{Ethical considerations}

All patients signed an informed consent to participate in a researcher-initiated clinical trial, as well as an informed consent for personal data processing. The study is in agreement with the Declaration of Helsinki. 


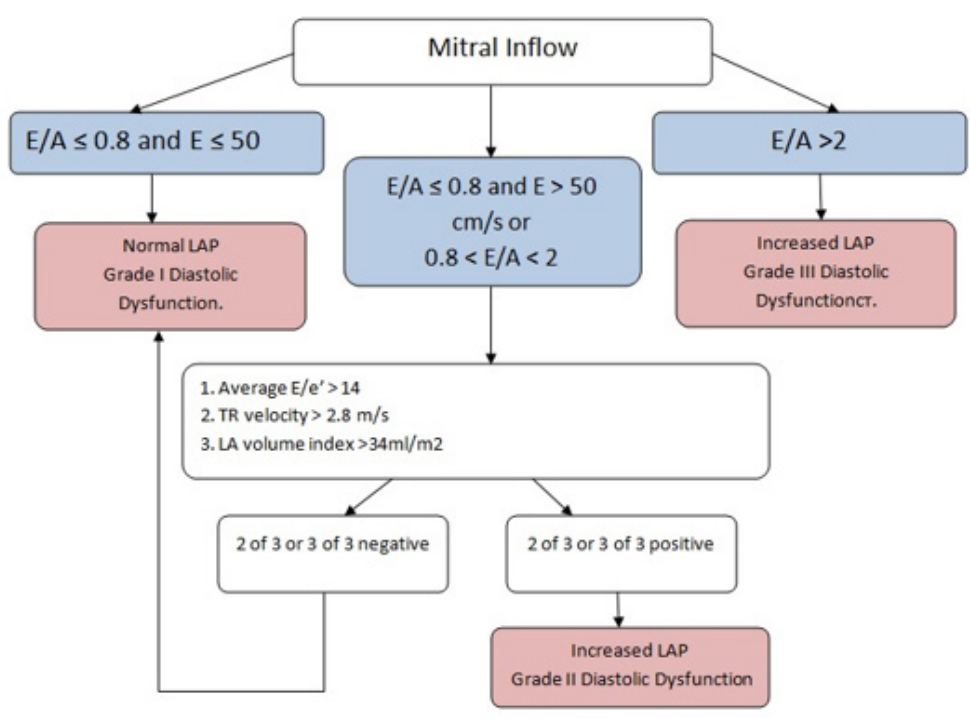

Figure 2: Parameters for determining the degree of diastolic dysfunction:

\section{Expected results}

Candesartan is a potent, highly selective, angiotensin II type 1 receptor blocker. It provides a strong, dose-dependent, and long-lasting antihypertensive effect. It does not affect glucose homeostasis and serum lipid profile and effectively reduces blood pressure and microalbuminuria in patients with hypertension and type 2 diabetes.

The effects of candesartan beyond lowering blood pressure have been proven repeatedly. The SCOPE study included 4964 elderly patients (70-89 years) with isolated systolic arterial hypertension. Treatment with candesartan resulted in a $42 \%$ reduction in the relative risk of stroke compared to the control group, and the effect was not related to the degree of decrease in BP [13-15].

The ACCESS study of 342 patients with hypertension and ischemic stroke showed that even a short course of candesartan treatment, started in the first 24 hours of the stroke, at a dose of $4 \mathrm{mg}$ (titrated if needed) significantly reduced subsequent cardiovascular morbidity and mortality. This effect is independent of the degree of decrease in BP [16].

Amlodipine is the most widely used calcium antagonist in real clinical practice worldwide. It has a smooth and long-lasting ( $>24$ hours) antihypertensive effect, preserving the circadian characteristics of BP. It does not lead to clinical deterioration, increased morbidity, and mortality in patients with heart failure [17].

Amlodipine has effects beyond lowering BP: in the CAMELOT study of nearly 2000 patients with coronary heart disease treated with standard therapy including statins and acetyl salicylic acid, the addition of amlodipine reduced the incidence of cardiovascular events by $31 \%$, hospitalization for angina pectoris by $42 \%$ and the incidence of coronary revascularization by $27 \%$ [18].

Treatment with candesartan and amlodipine in one tablet is in accordance with current recommendations for initial antihypertensive therapy. This combination reduces cardiovascular morbidity and mortality, as well as the incidence of stroke. The described investigator-initiated study will evaluate the effects of Bilamcar, Tchaikapharma High Quality Medicines on optimizing blood pressure, improving the parameters of diastolic dysfunction, and reducing LV hypertrophy.

\section{References}

1. Vitlyanova K, Tasheva R, Negreva M (2018) Clinical echocardiography. MU-Sofia, Bulgaria, pp. 101-119.

2. Kuneva Z, Marchev S, Tomov Il (1991) Diastolic function of the left ventricle. Contemporary Medicine 6: 10-14.

3. Nagueh S, Smiseth O, Appleton C, Benjamin FB, Hisham D, et al. (2016) Recommendations for the evaluation of left ventricular diastolic function by echocardiography: An update from the American Society of Echocardiography and the European Association of Cardiovascular imaging. Eur Heart J Cardiovasc Imaging 17(12): 1321-1360.

4. Halley CM, Houghtaling PL, Khalil MK, Thomas JD, Jaber WA (2011) Mortality rate in patients with diastolic dysfunction and normal systolic function. Arch Intern Med 171(12): 1082-1087.

5. Krasteva K (2017) Arterial hypertension in practice. Med info.

6. Williams B, Mancia G, Spiering W, Agabiti ER, Azizi M, et al. (2018) 2018 ESC/ESH Guidelines for the management of arterial hypertension. Eur Heart J 39(33): 3021-3104.

7. Petrovski P (2013) Clinical benefits of the angiotensin receptor blocker Candesartan - Clinical overview. Medinfo.

8. Petrovski P, Daskalov I (2013) Differentiated choice of angiotensin receptor blockers in the basic treatment of arterial hypertension. Medinfo 11: 11-18. 
9. Belcheva A, Marev P, Radev R (2009) Pharmacology. Steno, Varna, Bulgaria, pp. 121-122.

10. Penicka M, Gregor P, Kerekes R, Marek D, Curila K, et al. (2009) The effects of candesartan on left ventricular hypertrophy and function in non obstructive hypertrophic cardiomyopathy: a pilot, randomized study. J MolDiagn 11(1): 35-41.

11. Tomov I (2007) Cardiology. Znanie, Sofia 2: 81-99.

12. Georgiev B (2008) Clinical and pharmacological aspects of the angiotensin receptor antagonist Candesartan. Science of Cardiology 4: 189-192.

13. Spratt JC, Webb DJ, Shiels A, Williams B (2001) Effects of candesartan on cardiac and arterial structure and function in hypertensive subjects. J Renin Angiotens in Aldosterone Syst 2(4): 227-232.

14. Buarenski L (2011) Candesartan - a place in the treatment of hypertension and cardiovascular disease. Science of Cardiology 2: 106112.
15. Lithell H, Hansson L, Skoog I, Elmfeldt D, Hofman A, et al. (2003) The Study on Cognition and Prognosis in the Elderly (SCOPE): principal results of a randomized double-blind intervention trial. J Hypertens 21(5): 875-886.

16. Schrader J, Lüders S, Kulschewski A, Berger J, Zideket W, et al. (2003) The ACCESS Study: evaluation of Acute Candesartan Cilexetil Therapy in Stroke Survivors. Stroke 34(7): 1699-1703.

17. Clusin W (1999) Advances in Pharmacology. Academic Press 46: 253296.

18. Nissen S, Tuzcu EM, Libby P, Thompson PD, Ghali M, et al. (2004) Effect of antihypertensive agents on cardiovascular events in patients with coronary disease and normal blood pressure: the CAMELOT study: a randomized controlled trial. JAMA 292(18): 2217-2225. 